\title{
PEMAHAMAN FENOMENA PENGETAHUAN ARSITEKTUR KAMPUNG KOTA (KASUS : KAMPUNG BUSTAMAN BERBASIS KULINER)
}

\author{
Budi Sudarwanto ${ }^{*}$, Gagoek Hardiman², Agung B Sarjono \\ ${ }^{1}$ Mahasiswa Program Doktor pada PDTAP, FT UNDIP, Jl. Prof Sudarto, SH, \\ Kampus Tembalang Semarang, 50275 \\ ${ }^{2}$ Promotor pada PDTAP, FT UNDIP, Jl. Prof Sudarto, SH, \\ Kampus Tembalang Semarang, 50275 \\ ${ }^{3}$ Copromotor pada PDTAP, FT UNDIP, Jl. Prof Sudarto, SH, \\ Kampus Tembalang Semarang, 50275 \\ ${ }^{\star} E$-mail : budisud@gmail.com
}

\begin{abstract}
ABSTRAK. Tulisan ini bertujuan untuk mencari pemahaman tentang kampung kota dalam dimensi ilmu arsitektur kota, melalui pendekatan penelitian deskriptif kualitatif.Analisa matriks antara keilmuan arsitektur dan konteks keberlanjutan kampung kota dipahami sebagai upaya pengembangan pengetahuan tentang keunikan dan kompleksitas kampung kota berbasis kuliner. Penyusunan analisa matriks didasarkan kajian pustaka dan dilanjutkan dengan pendalaman empirik di lapangan dengan prosedur penelitian deskriptif kualitatif. Kampung masih dipandang sebagai sisi negatif dan sebagai beban perkotaan. Fakta empiris menunjukan bahwa kampung kota melakukan kegiatan kehidupan sehari-hari secara mandiri. Kampung memiliki kekuatan lokal dan kearifan lokal berbasis sosial budaya masyarakat kampung tersebut yang menjadi satu kekhasan kampung.
\end{abstract}

Budaya kampung mampu mendorong nilai tempat menjadi fenomenal dan mampu tetap bertahan atas pembangunan perkotaan. Diperlukan cara pandang berlawanan untuk mempertahankan ruang kampung kota. Kampung Bustaman salah satu kampung kota yang mampu memberikan inspirasi gagasan/ ide bagi kampung yang lain. Bustaman merupakan pengetahuan baru tentang arsitektur kampung di era kekinian, yang menunjukan kekuatan lokal yang dinamis dan sinergik. Kampung Bustaman menunjukan kelebihan dan kekurangan sebagai satu kampung kota pada umumnya. Kelebihan tersebut antara lain adalah potensial artefak dalam lingkungan kampung, kegiatan ekonomi lokal kuliner, keterbukaan sistem kekerabatan sosial, budaya masyarakat perkotaan kekinian, dan keterbukaan bagi pihak luar. Sedang kelemahannya adalah infrastruktur yang rentan, kondisi fisik lingkungan yang rendah, dan tingkat sosial ekonomi penghuni yang lemah.

Kata kunci: Fenomena arsitektur, kampung kota, kampung kuliner Bustaman

ABSTRACT.This paper is aimed to find an understanding of urban kampung in the dimensions of urban architecture, through a qualitative descriptive research approach. Matrix analysis between architectural and urban sustainability has been understood as an effort to develop knowledge about the uniqueness and complexity of culinary-based urban kampung. Preparation of matrix analysis based on literature review and continued with empirical deepening in field with qualitative descriptive research procedure. Kampung is still seen as a negative side and as an urban burden. Empirical facts show that urban kampung conduct activities of daily life independently. Kampung has local strengths and local wisdom based on the social culture of the kampung community which becomes one of the peculiarities of the kampung.

The village culture is able to push the place value into phenomenal and able to survive on urban development. It takes an opposite view to defend the urban space. Kampung Bustaman one of the urban kampung that is able to inspire ideas for other villages. Bustaman is a new knowledge of kampung architecture in the present era, which shows a dynamic and synergic local power. Kampung Bustaman shows advantages and disadvantages as a township in general. The advantages include potential artifacts in the village environment, culinary local economic activities, openness social kinship system, urban community culture and contemporary openness for outsiders. The weaknesses are the vulnerable infrastructure, the low physical condition of the environment, and the socio-economic level of the weak occupants.

Keywords: Architectural phenomenon, urban kampung, Bustaman culinary village 


\section{PENDAHULUAN}

Kampung merupakan bagian besar areal perkotaan yang ada di kota-kota besar Indonesia seperti Semarang. Kampung dipahami sebagai beban perkotaan atas proses modernisasi perkotaan. Kampung menunjukan 'stereotipe' yang negatif, artinya tidak memiliki kemampuan mendorong perubahan modernisasi perkotaan. Kampung menunjukan dampak negatif bagi proses perubahan modernisasi perkotaan. Kampung menunjukan kesemrawutan dan kekumuhan sebagai lingkungan hunian areal perkotaan. Kampung memiliki kompleksitas permasalahan yang rumit sebagai bagian dari prose modernisasi perkotaan.

Masalah istilah dan cara pandang kampung itu sendiri, kampung-kota atau kota kampung (Bakti Setiawan, 2000) [1]. Istilah dan atau cara pandang sebutan untuk 'kampung-kota' dalam pandangan dualisme sebagai polar yang bermuatan negatif. Negatif dalam segala cara pandang melihat kampung kota, baik dari aspek sosial, aspek ekonomi, aspek lingkungan, bahkan aspek budaya. Masingmasing aspek menunjukan atribut yang berkonotasi berada dibawah (bottom) dan terpinggirkan (marginal), serta posisi tawar rendah (bargaining), yang mendorong penurunan kualitas lingkungan kampung kota (quality).

Kampung dalam konteks perumahan perkotaan juga menunjukan permasalahan yang kompleks (Turner, 1976)(Palmer dan Patton, 1988). Kampung kota sebagai bagian pembentuk kota memiliki wujud yang berbeda dengan perumahan perkotaan. Kampung kota memiliki autonomy kuat dikarenakan modal kemandirian dan ikatan sosial yang kuat, namun mendominasi $70 \%$ bagian dari perkotaan. Didunia akademik bahkan diberikan sebutan informal settlement, illegal settlement, atau squatter settlement, slums, spontaneous settlement/shelter, atau unauthorized setllement'. [2]

Bahkan di era kekinian ada penelitian yang membuktikan bahwa kampungkota merupakan konsep awal pengembangan 'kota kompak'. Kompak dikarenakan kampung kota sebagai tumpuan semua warga untuk tempat bermukim dengan kepadatan tinggi, dan memiliki efisiensi guna lahan optimum, serta ketersediaan infrastruktur. (Roychansyah and Diwangkari, 2009) [2]
Pemerintah Indonesia dari tahun ke tahun melakukan pergeseran dan cara pandang kebijakan yang sesuai dengan konteks sosialekonomi-lingkungan seperti masalah kemiskinan dan kekumuhan, termasuk peningkatan kualitas lingkungan kampungkota, namun kenyataan yang terjadi adalah jauh dari keberhasilan. (Silas Johan, 1996; Kementerian PU, 2010; dalam Sandyawan Sumardi, 2016) [3]

Kampung kota dalam pemahaman arsitektural merupakan tempat dan lingkungan bermukim yang ada di areal perkotaan. (CA Doxiadis, 1968). Kampung kota sebagai tempat dan lingkungan bermukim warganya memiliki kekhasan (place identity) yang merupakan proses sistemik sosial budaya masyarakatnya (place attachment, place dependence, dan place making).(William, 1992, Jorgensen and Stedman, 2001)Ketiga hal tersebut yang membangun proses perubahan ruang kampung kota atas kearifan warga kampung. (sense of place). (Marcel Hunziker, dkk, 2007) [4]

Kampung kota menunjukan perubahan tata letak yang spontan, organik, dan tidak teratur. (Spiro Kostof, 1991). [5]. Dengan pemahaman pengetahuan konsep integrasi ruang (Marcus Zahnd, 1999) [6] dalam arsitektural maka ruang kampung kota yang kumuh dan liar merupakan ekspresi keruangan atas karakter masyarakatnya yang berpendidikan rendah dan miskin. Wujud tersebut merupakan pola terbangun oleh aktifitas kegiatan yang semrawut dan rumit dalam kampung. Hal ini diperlukan pengendalian ruang-ruang dalam kampung kota. (John Habraken, 2002) [7]

Pemahaman sistemik dalam konteks arsitektural menunjukan fenomena yang tidak optimal dalam pengembangan keruangan kampung kota. Kampung kota menunjukan 'kesemwrawutan dan kekumuhan' serta rentan terhadap perubahan perkotaan. Kampung dianggap sebagai beban perkotaan dan memiliki citra negatif. Kampung memiliki autonomi yang kuat dengan pertimbangan bahwa kampung memiliki modal sosial dan kemandirian yang besar. Kampung menjadi tumpuan warganya yang memiliki efisiensi lahan dan infrastruktur lingkungan.

Diperlukan cara pandang yang berlawanan arah dalam pengetahuan arsitektur kampung kota. Pengembangan pengetahuan arsitektur berbasis komunitas menjadi upaya untuk memperbaiki ruang kampung kota agar memiliki nilai positif. Ruang kampung kota 
Bustaman memiliki unsur-unsur terkait dengan fenomena ruang kampung kota yang berkelanjutan.

\section{METODE PENELITIAN}

Metoda yang digunakan didalam proses pendalaman awal penelitian adalah deskriptif kualitatif. Penggunaan analisa matrik untuk menjelaskan keterkaitan antara aspek arsitektural dengan aspek keberlanjutan kampung kota, sedangkan kualitatif adalah mengamati fenomena yang ada di lapangan, baik fisik dan kegiatan yang terjadi. Aspek arsitektural menyangkut aspek spatial kampung, aspek nilai kesetempatan kampung, dan aspek wujud kampung. Aspek keberlanjutan kampung kota terdiri atas perihal interaksi sosial, kegiatan ekonomi mikro, kehidupan budaya penghuni kampung kota, dan infrastruktur kampung. Diagram langkahlangkah penelitian adalah sebagai berikut :

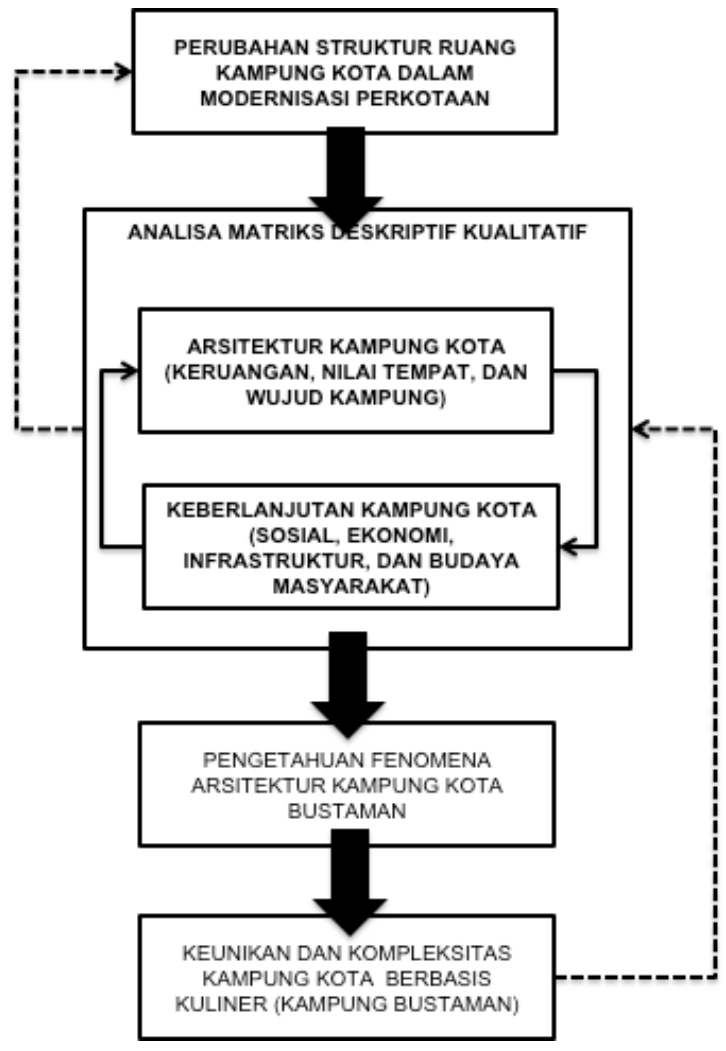

Gambar 1. Alur Pikir Penelitian Sumber : Peneliti, 2017
Tabel 1. Analisa Matriks

\begin{tabular}{|l|c|c|c|}
\hline Matriks 4 × 3 & $\begin{array}{c}\text { Spatial } \\
\text { kampung }\end{array}$ & $\begin{array}{c}\text { Kampung } \\
\text { sbg } \\
\text { tempat }\end{array}$ & $\begin{array}{c}\text { Wujud } \\
\text { kampung }\end{array}$ \\
\hline $\begin{array}{l}\text { Interaksi } \\
\text { sosial }\end{array}$ & DK1 & DK2 & DK3 \\
\hline $\begin{array}{l}\text { Ekonomi } \\
\text { local }\end{array}$ & DK4 & DK5 & DK6 \\
\hline Budaya & DK7 & DK8 & DK9 \\
\hline Infrastruktur & DK10 & DK11 & DK12 \\
\hline
\end{tabular}

Sumber : peneliti, 2017,

note : DK1 s/d DK 12 hasil kualitatis deskriptif matriks $4 \times 3$

\section{HASIL DAN PEMBAHASAN \\ Problematika kampung kota}

Kampung di perkotaan secara struktural mengalami dampak perubahan ruang yang tidak strategis. Artinya banyak kampung mengalami penurunan kualitas lingkungan, yaitu kumuh, tidak sehat, infrastruktur rendah, dan padat penghuninya. Fakta bahwa kampung tidak tergarap oleh kebijakan pemerintah kota adalah jelas. Kampung lebih dominan memampukan dirinya sendiri secara mandiri.

Aspek sosial menjadi fokus utama yang diteliti oleh para peneliti kota, seperti partisipasi penghuni (Handayani, 2008), kreatifitas kampung (Kustiwan, 2015), modal sosial (Rolalisasi, 2013), sumber tenaga kerja murah (Newberry, 2013), kapasitas penghuni, dan daya juang kampung (Putra, 2013). Permasalahan lingkungan fisik dianggap sebagai dampak aktifitas sosial ekonomi penghuni kampung (Harjoko, 2009). $[8,9,10,11,12,13]$

Karakter ruang ketiga sebagai ruang transisi ada dikarenakan adanya interaksi yang intens dalam aktifitas penguhuni kampung. (Damayanti, 2016) Ruang ketiga ini menjadi karakter khas ruang kampung kota. (Nor Zarifah Maliki, 2014) Aktifitas yang menggerakan kehidupan kampung berbeda antara kampung satu dengan yang lain. Artinya bahwa kekuatan lokal antara kampung satu dengan kampung yang lain berbeda. (Tim Bunnell (2002). [14, 15]

Problematika kampung kota menunjukan kompleksitas dalam konteks struktural dalam modernisasi perkotaan. Kecenderungan perubahan radikal terhadap ruang kampung kota akibat urbanisasi semakin nyata. Menjadi satu pertanyaan adalah bagaimana keberlanjutan ruang kampung kota? Tentunya dibutuhkan pendekatan lain sebagai upaya pengembangan ruang kampung kota, yaitu berbasis komunitas/warga kota. 


\section{Ruang Kampung Kota}

Kampung-kampung yang ada di kota Semarang menunjukan gejala 'menguap', hanya tinggal nama. Modernisasi perkotaan membuat kampung kota semakin terpinggirkan, baik secara struktural maupun alamiah, karena kampung memiliki keterbatasan berlebih kecuali ikatan sosial penghuninya. Modernisasi perkotaan menyebabkan perubahan struktur ekonomi, budaya masyarakat kota, dan lingkungan fisik perkotaan, termasuk perubahan nilai-nilai sosial kemasyarakatan. Modernitas perkotaan melalui alih fungsi lahan dari agraris ke industri, yang memuat sarat modal dan teknologi.

Aspek sosial, aspek ekonomi, dan lingkungan perkotaan dan dengan segala kegiatan perubahan modernitas tersebut menjadikan ruang perkotaan dan tempat-tempat yang ada di area perkotaan wujudnya menjadi berubah. Kampung kota merupakan komponen struktur ruang kota yang mengalami perubahan isi (content), akibat desakan eksternal dan perubahan internal yang juga merubah wujud fisiknya (container), yang akibatnya nilai kekhasan kampung tersebut lenyap (contextual). Kampung kota memiliki kekhasan sebagai komponen perkotaan yang padat penghuni, infrastruktur rendah, tidak teratur, dan memiliki ikatan sosial yang kuat, serta memiliki keunikan aktifitasnya.

Bila kampung kota lenyap atau hilang maka wujud fisik arsitektural tidak dapat ditelusuri lagi. Untuk memahami wujud arsitektural dalam skala perkotaan dengan menggunakan kaidah-kaidah integrasi arsitektural dari Roger Trancik dalam Finding Lost Space. Ada tiga kaidah, yaitu lingkage, figure ground, dan place. Maka untuk memahami wujud arsitektural kampung (the shaping of kampong) harus mendalami 'place' yang menjadi ikatan terhadap 'space' dan 'shape'.

\section{Kampung Bustaman}

Kampung Bustaman adalah salah satu kampung lama kota yang terletak di RW III, Kelurahan Purwodinatan, Kecamatan Semarang Tengah, Kota Semarang. Kampung Bustaman memiliki luas wilayah sekitar $0,6 \mathrm{Ha}$ dan terdiri atas 2 wilayah RT, yaitu RT 04 dan RT 05 . Kampung Bustaman memiliki jumlahpenduduk sebanyak 354 jiwa atau 101 KK. Kepadatan penduduk di Kampung Bustaman mencapai 590 jiwa/Ha dan tergolong sebagai permukiman berkepadatan sangat tinggi. Kampung Bustaman masih didominasi oleh warga berusia produktif, yaitu antara $15-60$ tahun sekitar $65 \%$ dari total jumlah penduduk. Kampung Bustaman memiliki nilai sejarah dan beberapa artefak fisik lingkungan yang mampu membangun karakter kampung Bustaman sehingga dapat dikenal masyarakat luas. Nama kampung kota Bustaman berasal dari Kyai Kertoboso Bustam, seorang tokoh terkenal jaman pemerintahan Belanda juga kakek buyut dari Raden Saleh. Raden Saleh sendiri seorang pelukis kondang modern hybrid kebanggan Indonesia yang pernah belajar ke Eropa.

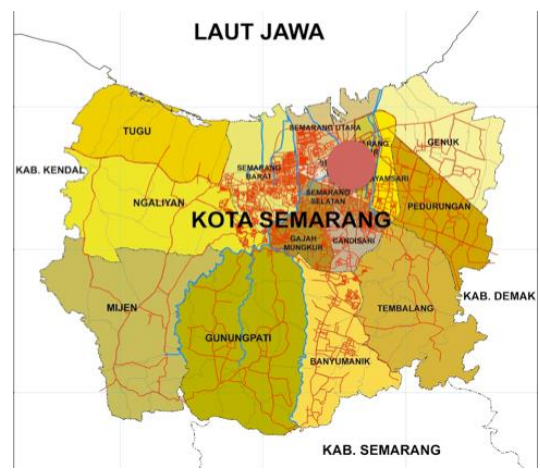

Gambar 2. Lokasi Kampung Bustaman Sumber : petasmg.com

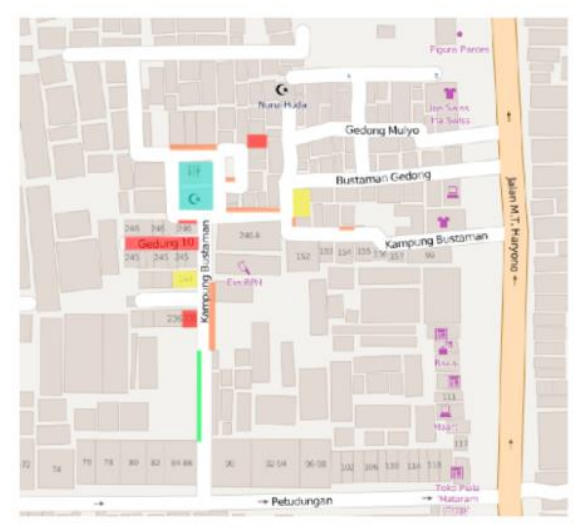

Gambar 3. Kampung Bustaman Sumber : www.petasmg.com

Ibu Sri Hartatik adalah satu keturunan langsung dalam silsilah Raden Saleh yang masih hidup sampai sekarang, dan bertempat tinggal dikampung bustaman ini. Ada bapak Harry Bustaman juga merupakan tokoh masyarakat yang masih memiliki hubungan saudara dengan keluarga besar Bustaman dan juga memiliki rumah di kampung Bustaman. 


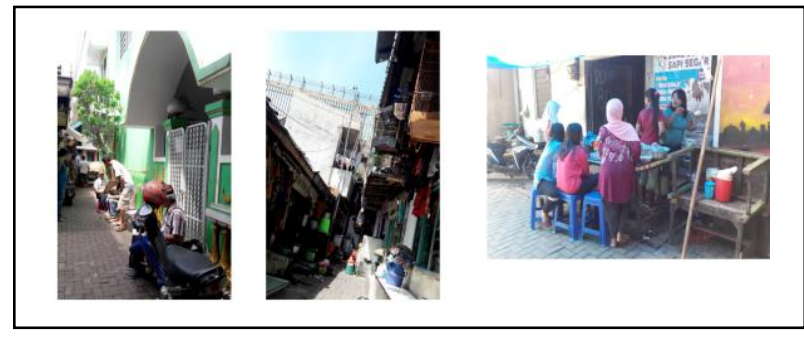

Gambar 4. Masjid Kampung, Gedong 10, dan RPH Sumber : Survey Lapangan, 2017

Artefak fisik lain adalah sumur tua peninggalan kolonial yang masih digunakan sampai sekarang, sehingga ada program sanitasi lingkungan berbasis masyarakat (SANIMAS) berjalan dengan baik hingga kini. RPH atau rumah pemotongan hewan lama ada di kampung Bustaman namun kondisi sekarang tidak dapat digunakan, bahkan dijadikan gudang kampung. RPH ini masih dalam proses sengketa kepemilikan. Adanya RPH ini membuat penghuni kampung Bustaman terampil membuat olahan masakan daging kambing seperti sate, gule, tongseng, betik, dll menjadi ciri khas kampung Bustaman dan bahkan menjadi daya tarik kampung hingga kini. Gule bustaman sangat diminati banyak warga kota Semarang. Gedong 10 (sepuluh) adalah hunian padat disalah satu sudut ruang di kampung Bustaman, ratio hunian menunjukan kepadatan yang tinggi.

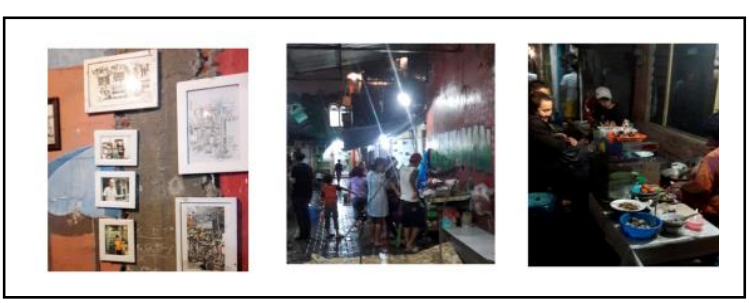

Gambar 5. Tengok Bustaman III Sumber : Survey Lapangan, 2017

Ada beberapa budaya yang tetap dilestarikan sampai sekarang disamping kegiatan religi masyarakat kampung Bustaman, yaitu kuliner petengan, gebyur bustaman, dan tengok bustaman. Budaya ini dibangun dandilestarikan bersama antara masyarakat kampung Bustaman dengan LSM Hysteria. Hysteria adalah komunitas yang peduli terhadap permasalahan pengembangan 'kampung kota' untuk mewujudkan kota berbudaya.

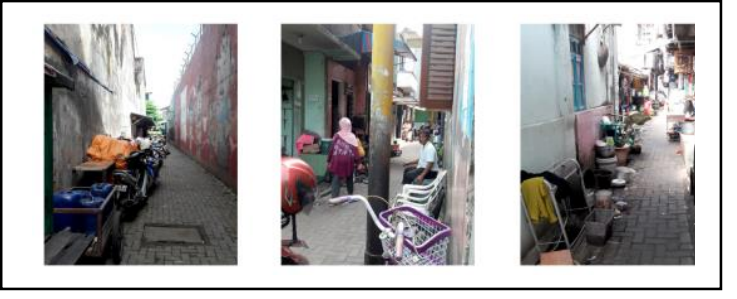

Gambar 6. Infrastruktur lingkungan kampung Bustaman Sumber : Survey Lapangan 2017

Fenomena kampung Bustaman menunjukan fakta dan data berkarakter informal, ada keterbatasan ruang, lingkungan kurang layak huni, pemanfaatan ruang tidak sesuai fungsi karena sempit, infrastruktur lingkungan rendah. Banyak aktifitas sehari-hari menggunakan ruang lorong kampung (jalan kampung) sangat dominan, seperti parkir motor, meletakan alat memasak dan barang dagangan, mengobrol dan bersosialisasi warga kampung. Bahkan di sudut jalan buntu ditempatkan sebagai gudang kampung, barang-barang tidak digunakan diletakan dilorong buntu tersebut.

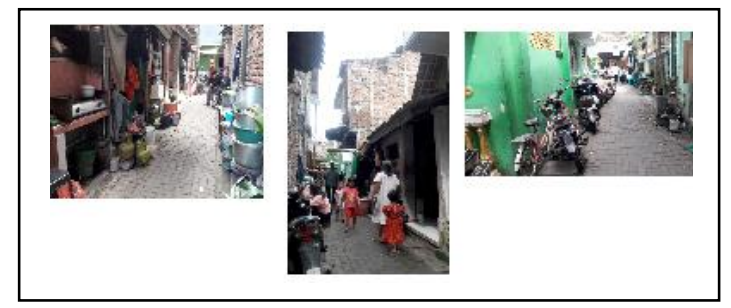

Gambar 7. Kehidupan Penghuni Kampung Sumber : Survey Lapangan 2017

Karakter bangunan hunian yang sempit dan berdempetan serta tidak ada pencahayaan alami yang cukup menjadikan gelap didalam pada sianghari. Hampir sebagian besar rumah di bustaman tidak memiliki ruang terbuka termasuk teras rumah. Bila adapun teras rumah tersebut sangat sempit dan digunakan untuk berjualan atau tempat mengobrol, bahkan membangun tembok-tembok tempat duduk yang mengurangi lebar lorong jalan. Sanitasi lingkungan tidak memenuhi persyaratan sanitasi lingkungan hunian, kecil, sempit, dan kurang lancar.

\section{Fenomena ruang kampung Bustaman \\ Konteks karakter sosial warga \\ (matriks DK1 s/d DK 3)}

Warga kampung Bustaman berinteraksi diantara sesama warga menunjukan fenomena beragam, terkait dengan hubungan sosial individu maupun kelompok, maupun kepentingan ekonomi. Dengan kepadatan yang tinggi dan ruang yang terbatas mengakibatkan ruang kampung kota bustaman 
sangatlah sesak, khususnya kegiatan-kegiatan sibuk pagi dan sore hari.

Tempat-tempat tertentu menjadi tempat kumpul dan bersosialisasi yang paling padat, yaitu pertigaan depan masjid dan ruang teras depan MCK atau ruang serbaguna. Event gebyuran, tengok bustaman, atau kegiatan pertemuan warga selalu menggunakan ruang bersama depan MCK dan ruang serbaguna kampung Bustaman. Namun ada tempattempat tertentu digunakan sebagai kumpul untuk kepentingan kegiatan ekonomi, seperti ruang publik depan $\mathrm{RPH}$, sudut ruang depan rumah haji Yusuf sebagai tempat nongkrong anak muda.

Pos jaga kampung juga sebagai tempat berkumpul untuk kepentingan jaga keamanan kampung. Area gedong 10 yang padat penghunianya tidak pernah sepi dari kerumunan atau interaksi warga, khususnya warga yang tinggal di gedong sepuluh. Tidak terlepas koridor jalan pada sudut-sudut pertemuan koridor gang jalan kampung juga sebagai interaksi sosial, termasuk depan masing-masing rumah warga sebagai ruang sosial pada level kelompok kecil.

Arti ruang kampung sebagai tempat bermukim mampu membentuk karakter bentuk kampung kota. Kampung Bustaman memperlihatkan fenomena sosial-budaya dan ekonomi yang sangat kontekstual sebagai ruang kampung kota yang bertahan. Hal ini tidak terlepas atas pengaruh kegiatan ekonomi lokal kuliner kambing dan aspek sejarah kampung Bustaman. Pola sirkulasi berkegiatan dalam kampung menunjukan alur hubungan diantara tempat-tempat simpul bersosialisasi. Struktur pola sirkulasi sangat rumit dan tumpang tindih selama proses berinteraksi warga dalam konteks berkehidupan sehari-harinya.

Nilai sejarah kampung Bustaman memberikan struktur hubungan kekeluargan di sebagian warga kampung Bustaman. Masih banyak terdapat keterikatan sebagai keluarga besar dalam silsilah Raden Saleh dan budaya kampung kota yang disebut sebagai 'peknggo', ngepek tonggo, artinya hubungan ikatan keluarga tetangga dapat tetangga.

\section{Konteks kegiatan ekonomi kampung}

\section{(matriks DK4 s/d DK 6)}

Kegiatan ekonomi lokal olahan daging kambing merupakan kekhasan kegiatan warga kampung Bustaman didalam memenuhi kebutuhan ekonomi keluarga. Proses produksi yang lengkap dan peran warga terlibat didalamnya membuat kuliner olahan daging kambing terkenal meluas keluar kampung Bustaman. Disamping masih terdapat usaha kuliner yang lain ada beberapa usaha kelontong dengan membuka warung didepan rumah masing-masing.

Lengkapnya produksi kuliner olahan daging kambing dari awal penyembelihan sampai dengan penjualan, tentunya membutuhkan ruang dan tempat yang memadai agar mampu memberikan layanan dan memperoleh margin usaha. Ruang penyembelihan berskala kecil dan besar ada di ruang kampung kota Bustaman. Namun RPH yang ada sekarang tidak berfungsi maka dikerjakan dihalaman dan didalam rumah. Haji Toni yang memilik kapasitas lebih kurang 75 ekor per hari dikerjakan didalam rumah dan sebagian dilakukan diteras rumah sedangkan $\mathrm{H}$ Yusuf dengan kapasitas lebih kurang 7 ekor per hari dilakukan diteras rumah.

Peran lain untuk membersihkan kambing setelah dipotong dilakukan oleh beberapa warga kampung dengan spesialisasi masingmasing. Artinya kegiatan penyiapan daging kambing siap-olah terdistribusi ke warga sebagai tambahan pendapatan bagi warga bekerja sebagai tukang potong daging. Peran membuat bumbu olahan daging kambing untuk gulai dan tengkleng dilakukan oleh 3 orang warga kampung yang keahlian membuat resep tersebut merupakan hasil warisan.

Peran masing-masing warga dalam kegiatan ekonomi lokal banyak yang dikerjakan di teras dan halaman rumah. Dapur rumah hampir sebagian terletak didepan hunian. Tata letak hunian kampung Bustaman menunjukan kekhasan sebagai kampung kota yang memiliki keterbatasan ruang gerak karena nilai ekonomi lahan pusat kota.

Hunian warga kampung menjadi memiliki nilai ekonomi yang strategis, karena tata letak ruang dapur yang didepan memungkinkan kemudahan dalam bergerak dan berproduksi terkait dengan memenuhi kebutuhan hidup keluarga. Alur pegerakan kegiatan ekonomi warga membuat kompleksitas ruang teras dan koridor jalan kampung Bustaman. Tumpang tindih kegiatan dan pergeseran fungsi ruang relatif cepat sesuai dengan kebutuhan kegiatan warga kampung. Kegiatan kehidupan warga yang sangat cepat perubahannya tersebut mampu membangun nilai-nilai simbol keruangan kampung Bustaman. Bustaman terkenal sebagai kampung kuliner olahan 
daging kambing, seperti sate, gule, dan tengleng.

\section{Konteks kebiasaan warga}

(matriks DK7 s/d DK 9)

Nilai sejarah kampung melalui artefak yang ada di lingkungan kampung kota Bustaman menunjukan budaya warga didalam melestarikan karakter kampung kota Bustaman sangat kuat. Kegiatan bersosialisasi secara kelompok dipelihara hingga sekarang, seperti tradisi gebyuran, tengok bustaman, pasar kuliner malam, maupun kegiatankegiatan dalam kerangka membangun sifat gotong-royong warga. Meskipun tetap ada infiltrasi budaya akibat adanya perkembangan teknologi informasi, namun kearifan lokal budaya warga melalui tokoh masyarakat seperti Bpk Hari Bustaman bergerak membangun kampung Bustaman.

Budaya warga merupakan pernik-pernik yang dapat memperlambat pengembangan kampung Bustaman. Konflik dan persaingan masih tetap ada namun tetap dapat diredam dalam konteks persaingan individu dan keluarga dalam konteks persoalan keluarga maupun utang-piutang. Artinya tidak memperlemah persatuan dan kesatuan warga kampung, meskipun ada perbedaan pendapat namun dalam jangkauan pengelolaan komunitas kampung Bustaman.

Faktor eksternal LSM dan peran pemerintah kota mendorong secara perlahan kekuatan komunitas kampung Bustaman agar lebih mampun mandiri. Warga pendatang berasal dari Kudus dan Jepara melihat ada peluang budaya ekonomi yang menguntungkan. Kedatangan mereka mengambil peran sebagai penjual kuliner olahan daging yang dibawa keluar kampung memiliki makna positif dan negatif. Positif membantu promosi kekhasan kampung Bustaman, disisi lain mengambil peran yang dimiliki warga kampung Bustaman.

Peran pemuda kampung Bustaman belum memperlihatkan keasadaran atas kekuatan lokal dan kearifan lokal kampung kota Bustaman. Perkembangan teknologi informasi membuat peran kepemudaan menjadi tidak terlibat langsung dalam kearifan lokal. Seharusnya dalam konteks budaya kampung maka ikatan emosi warga berada pada fungsi maksimal. Diperlukan kesadaran generasi penerus kampung Bustaman, kalau tidak akan kampung Bustaman akan seperti kampung kota yang lainnya.
Konteks lingkungan fisik kampung (matriks DK10 s/d DK 12)

Tidak jauh berbeda dengan konteks pengertian kampung pada umumnya. Kampung Bustaman memiliki lingkungan permukiman berkualitas rendah, meskipun bagi warga kampung bernilai ekonomi tinggi. Kumuh dan tidak layak sebagai fungsi hunian namun tetap saja warga kampung tersebut betah tinggal didalamnya, meskipun dengan berdesak-desakan.

Keterbatasan akses dan ekonomi warga kampung Bustaman membuat kemampuan untuk meningkatkan kualitas lingkungan fisik kampung terbatas. Lebih mengutamakan kebutuhan hidup sehari-hari jika dibandingkan dengan memperbaiki lingkungan fisik. MCK berbasis masyarakat masih tetap berfungsi secara optimal, dan sumur tua yang ada dekat masjid dan ruang serbaguna masih digunakan sebagai sumber air. Meskipun begitu masih ada pasokan air dari luar kampung mengingat kebutuhan volume air yang tinggi.

Tingkat perekonomian yang rendah menjadi kendala utama dalam memelihara lingkungan fisik kampung Bustaman. Kondisi fisik yang relatif kurang layak huni membutuhkan intervensi pihak luar khsusunya pemerintah kota. Program kampung tematik diharapkan mampu meningkatkan kelemahan lingkungan fisik kampung. Perbaikan RPH yang tidak berfungsi akan digunakan sebagai dapur bersama kampung warga.

\section{Pengetahuan ruang kampung Bustaman}

Keruangan kampung Bustaman menunjukan ruang publik bagi penghuni kampung. Kuatnya ikatan dan interaksi sosial menjadikan keruangan kampung sangat random dan kompleks. Kadang digunakan untuk fungsi ekonomi dan juga fungsi sosial dengan tingkat mobilisasi dan alih fungsi yang sangat ketat. Ada simpul-simpul keruangan yang bersifat bersama dan khusus mengingat keterbatasan ruang dan ketersediaan infrastruktur yang lemah.

Lorong jalan hampir secara keseluruhan menunjukan multifungsi antara untuk kepentingan penghuni maupun kepentingan kampung. Seperti pada kegiatan-kegiatan tertentu harus dengan menutup koridor jalan kampung. Masjid kampung dan ruang pertemuan warga serta pos jaga kampung adalah simpul-simpul keruangan kampung yang sangat tinggi intensitas kegunaannya sebagai ruang bersama. 
Masalah keruangan terkait dengan alih guna ruang dan keterbatasan berbagi ruang menjadikan nilai ruang sebagai tempat ikatan komunal warga kampung. Dampak dari hal tersebut menjadi tidak teratur, semrawut dan tidak layak fungsi sebagai infrastruktur lingkungan.

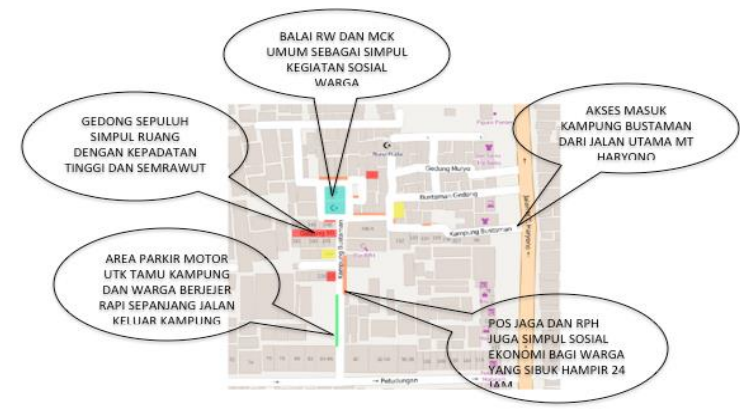

Gambar 8. Simpul-simpul sosial ekonomi Kampung Bustaman

Sumber : survey lapangan, 2017

Aktifitas ekonomi mikro kuliner olahan daging kambing menjadi pengikat makro lingkungan kampung sebagai figur kampung yang mandiri dan kompak sehingga mampu beradaptasi dan merespon tekanan modernisasi ekonomi perkotaan, meskipun dalam tatanan yang konvensional dalam usaha pengembangan kegiatan ekonominya.

Nilai kesetempatan di lingkungan kampung menunjukan beragam tujuan dan kemanfaatan. Kepadatan dan keterbatasan ruang mendorong kegunaan ruang dipakai secara optimal oleh masyarakat kampung. Namun pada tempat-tempat tertentu masih ada yang 'lost', artinya digunakan sebagai gudang penyimpanan dalam skala bersama kampung. RPH dan sudut sudut ruang pojok yang tidak dilalui maupun terjangkau kegiatan sehari-hari.

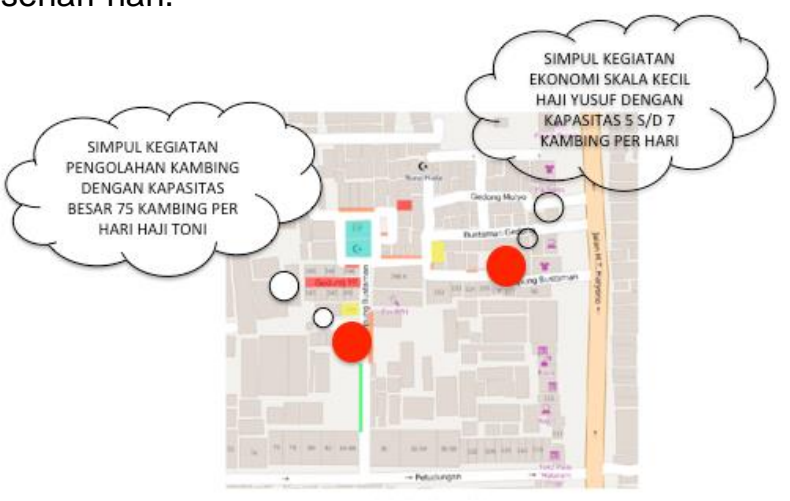

Gambar 9. Simpul kegiatan pengolahan kambing di kampung Bustaman

Sumber : Survey Lapangan 2017
Wujud kampung atau dapat disebut visual kampung kota menunjukan tidak ada beda dengan gambaran kampung-kampung kota yang lain. Namun yang membedakan adalah kampung Bustaman sangat hidup dalam konteks 24 jam. Kegiatan awal di mulai dari jam 02.00 malam sudah dimulai kegiatan penyembelihan kambing yang dilanjutkan dengan kegiatan lainnya. Terus bergeser dan bergerak dengan kegiatan-kegiatan lain dan terjadi pada simpul-simpul kegiatan yang membangun nilai keruangan kampung yang sangat kompleks.

\section{KESIMPULAN}

Kampung Bustaman secara sekilas sebagai kampung yang dipahami seperti kampungkampung lain di berbagai kota di Indonesia. Kampung yang rendah kualitas lingkungannya, padat penghuni, sosial ekonomi masyarakatnya dalam kategori rendah, keterbatasan ruang dan infrastruktur lingkungan. Menunjukan nilai negatif yang membebani dalam proses modernisasi perkotaan.

Keunikan dan kompleksitas kampung Bustaman dibangun atas dinamika dan pegerakan kegiatan sosial ekonomi masyarakat yang hidup. Hidup dipahami sebagai visualisasi khas kampung kota. Sehingga secara fisik, wujud kampung dapat dilihat, digambarkan, dan dirasakan sebagai kampung yang berjuang secara mandiri dan konvensional tanpa pengaruh luar.

Dibalik semua tentang gambaran makro maupun mikro kampung tentunya ada motif tersembunyi bagi masyarakat kampung Bustaman dengan berbagai upaya untuk mempertahankan dan berbagi kehidupan kampung kota.

\section{UCAPAN TERIMA KASIH}

Disampaikan terima kasih masyarakat kampung Bustaman, terutama Bpk. Harry Bustaman dan Bpk Sugiono, serta warga kampung Bustaman yang telah memberikan kesempatan dan dukungan informasi terkait dengan kegiatan penelitian.

\section{DAFTAR PUSTAKA}

[1] Setiawan, Bakti. (2010). Kampung Kota Dan Kota Kampung: Tantangan Perencanaan Kota Di Indonesia. Pidato Pengukuhan Jabatan Guru Besar Dalam IImu 
Perencanaan Kota Universitas Gadjah Mada, Yogyakarta.

[2] Roychansyah, M.S.; Diwangkari, A. (2009). Kampung Oriented Development Model: A Rapid Appraisal of Local Communities. Proceeding of CIB - W110 Meeting and Conference "Sustainable Slum Upgrading in Urban Areas", Surakarta, 16 April 2009, pp. 119-134.

[3] Sandyawan S. (2016). Reformasi Kampung Kota. Direktur LSM Ciliwung Merdeka.

[4] Hunziker, Marcel, dkk .(2007). Space and Place - Two Aspects of the Humanlandscape Relationship. F. Kienast, O. Wildi \& S. Ghosh (eds.) , A Changing World. Challenges for Landscape Research, 47- 62. (c) 2007 Springer.

[5] Kostoff, Spiro. (1991). The City Shapes.

[6] Zahnd, Marcus. (1999). Perancangan Kota secara Terpadu. Kanisius Seri Strategi Arsitektur 2. Yogyakarta

[7] Habraken, John. (2002). The Uses Of Levels. Keynote Address Unesco Regional Seminar on Shelter for the Homeless Seoul 1988As re-issued by Open House International Vol. 27 no. 22002

[8] Handayani, Sri. (2008). Partisipasi Masyarakat Kampung Kota Untuk Meningkatkan Kualitas Lingkungan Permukiman (Kasus: Permukiman Kampung Kota Di Bandung). Disertasi Institut Pertanian Bogor.

[9] Kustiwan, Iwan, Ibrahim Ukrina, dan Astri Auliaa. (2015). Identification of the Creative Capacity of Kampong's Community towards Sustainable Kampong (Case Studies: Cicadas and Pasundan Kampong, Bandung): A Preliminary Study. Procedia - Social and Behavioral Sciences 184 (2015) 144-151.

[10] Rolalisasi, Andarita, Happy Santosa, Ispurwono Soemarno. (2013). Social capital of urban settlement"; Psychology and Behavioral Sciences 2013; 2(3): 83-88 \begin{tabular}{llll}
\hline Published online June 10,2013 &
\end{tabular} (http://www.sciencepublishinggroup.com/j/pbs) doi: 10.11648/j.pbs.20130203.11

[11] Newberry, Jan. (2006). Double Spaced: Abstract Labour in Urban Kampung. Department of Anthropology University of
Lethbridge 4401 University Drive Lethbridge, Alberta T1K 3M4

[12] Putra, Budi Arlius. (2013). The Survival Phenomenon of Kampong Kuningan Amidst The Development of Mega Kuningan Business-area in Jakarta. IJSER (C) 2013

[13] Harjoko, Triatno Yudo. (2009). Urban Acupuncture: An Alternative Purposive intervention to urban development to generate sustainable positive ripples for an 'Aided Self-Help' Kampung Improvement. Informal Settlements and Affordable Housing 2009.

[14] Damayanti, Rully Dan Florian Kossak. (2016). Extending Kevin Lynch's concept of imageability in third space reading; case study of Kampungs, Surabaya-Indonesia. ITU A|Z • Vol 13 No 1 • March 2016 • 57-67.

[15] Maliki, Nor Zarifah , Aldrin Abdullah, Azizi Bahauddin. (2014). Recalling the Transitional Space: City home and Kampung home. Procedia - Social and Behavioral Sciences 170 (2015) 605 - 612 diunduh 15 Februari 2017. 
